\title{
The context of prostate cancer genomics in personalized medicine (Review)
}

\author{
YANLING LIU \\ Department of Oncology-Pathology, Karolinska Institutet, Stockholm SE-171 76, Sweden
}

Received September 6, 2016; Accepted January 26, 2017

DOI: $10.3892 / \mathrm{ol} .2017 .5911$

\begin{abstract}
Prostate cancer is one of the most common types of cancer in males. Heterogeneous genomic aberrations may lead to prostate cancer onset, progression and metastasis. This heterogeneity also contributes to the variety in cancer risk and outcomes, different drug responses and progression, observed between individual patients. Classical prognostic factors, including prostate-specific antigen, Gleason Score and clinical tumor staging, are not sufficient to portray the complexity of a clinically relevant cancer diagnosis, risk prognosis, treatment choice and therapy monitoring. There is a requirement for novel genetic biomarkers in order to understand the oncogenic heterogeneity in a patient-personalized clinical setting and to improve the efficacy of risk prognosis and treatment choice. A number of biomarkers and gene panels have been established from patient sample cohort studies. These previous studies have provided distinct information to the investigation of heterogeneous malignancy in prostate cancer, which aids in clinical decision-making. Biomarker-guided therapies may facilitate the effective selection of drugs during early treatment; therefore, are beneficial to the individual patient. A non-invasive approach allows for convenient and repeated sampling to screen for cancer and monitor treatment response without the requirement for invasive tissue biopsies. With the current availability of numerous advanced technologies, reliable detection of the minimal tumor residues present following treatment may become clinical practice and, therefore, inform further in the field of personalized medicine.
\end{abstract}

Correspondence to: Dr Yanling Liu, Department of OncologyPathology, Karolinska Institutet, R8:04 Solna, Stockholm SE-171 76, Sweden

E-mail: yleen.liu@gmail.com

Key words: prostate cancer, genomic heterogeneity, genetic biomarker, cancer detection, risk prognosis, treatment prediction, non-invasive test

\section{Contents}

1. Introduction

2. Prostate cancer genomics and molecular subtypes

3. Genetic biomarkers for screening and detection of early cancer

4. Genetic biomarkers for risk stratification of aggressive cancer

5. Expression score of a panel of genetic biomarkers for risk stratification

6. Non-invasive genetic biomarker test

7. Therapies targeting to tumor genetic aberrations

8. Discussion

\section{Introduction}

Cancer is a genetic disease. DNA sequence mutation, deletion/insertion, gene fusion, alterations of copy number and epigenetic in proto-oncogenes and tumor suppressor genes all contribute to cancer susceptibility. Prostate cancer is one of the most frequently diagnosed types of cancer in males, but the potential risk and outcome are variable between patients $(1,2)$. The androgen-receptor (AR) signaling axis serves an important role in prostate tumorigenesis and progression (3). Upon the binding of androgen ligands, the transcription factor AR is translocated into the nucleus to activate the expression of genes that are involved in cell proliferation and growth, the inhibition of apoptosis, protease signaling and the inflammatory response $(4,5)$. The epithelial-mesenchymal transition (EMT) promotes cancer progression to metastasis. The EMT of a tumor cell proceeds through actin cytoskeletal cell-matrix interaction and extracellular matrix remodeling to be able to invade and metastasize (6-8). An activated AR signaling axis suppresses the transcription of E-cadherin, which leads to breakdown of cell-cell adherens junctions and the onset of EMT (6).

Classical prognostic factors, including prostate-specific antigen (PSA) level, biopsy-based Gleason Score (GS) and clinical tumor staging, are typically used to stratify cancer risk for biopsy and clinical decision-making (1). For the majority of patients with a low-risk cancer, treatment may not be required due to the small and slow-growing tumor $(9,10)$. Active surveillance may be the optimal choice to avoid the side effects associated with treatments. For high-risk cancer, 
it is typical that individual patients have different responses to the same drug and the current standard treatment option is not consistently optimal for all patients, compared with choosing effective therapy for the individual patient (11). The different drug responses may be attributed to the genetic variances between individual patients and their respective tumors (12). Therefore, there is a requirement for novel biomarkers that target distinct cancer genomic aberrations, which may be used to understand oncogenic heterogeneity, improve the diagnosis of cancer risk and progression, and to aid the prediction of an effective therapy using a personalized approach $(13,14)$.

\section{Prostate cancer genomics and molecular subtypes}

In prostate cancer cells, androgen-regulated transcription factors, including Forkhead Box A1, GATA-binding protein 2 and Octamer-binding protein 1, are recruited to AR chromosome binding sites $(15,16)$. In coordination with AR, the AR-regulated signaling pathway is activated to modulate the overexpression of PSA, transmembrane protease serine 2 (TMPRSS2) and other genes. TMPRSS2, a transmembrane serine protease, is expressed specifically in the prostate gland $(15,16)$. ETS transcription factors are important regulators of cell proliferation, differentiation and apoptosis (17). Androgen-regulated ETS gene fusions are the most commonly identified genetic alterations and are present in $>50 \%$ of primary and metastatic prostate cancer cases $(15,18)$. Among the established gene fusions, transcriptional regulator $\operatorname{Erg}(E R G)-T M P R S S 2$ is frequently identified. Of the established tumorigenic somatic mutations, speckled-type POZ protein $(S P O P)$, tumor protein 53 (TP53), phosphatase and tensin homolog (PTEN), ataxia telangiectasia mutated (ATM) and catenin $\beta 1$ are the most frequently mutated cancer-driving genes (18), and these mutations were also identified by the Integrative Onco Genomics database (19). SPOP was previously established to be involved in DNA double-strand break repair, and when mutated it is associated with genomic instability in prostate cancer (20). SPOP mutations and ETS gene fusions are categorized as two primary molecular subtypes according to the genetic heterogeneity of the tumors $(18,19)$.

In the progression of primary to aggressive, of androgen-dependent to castration-resistant and of localized to metastatic, cancer cells develop numerous genetic and epigenetic aberrations $(18,21,22)$. AR signaling may be altered through AR copy number amplification, gene mutation and alternative splicing variants, to drive cancer cell growth in androgen-deprived environments (5). A high DNA copy number alteration in the tumor genome is associated with disease relapse and metastasis (23). Deletion of PTEN, TP53 mutations and ETS gene fusions are frequently present in castration-resistant and metastatic tumors $(21,22)$. Epigenetic alterations, including genomic hypermethylation, are associated with advanced stages of cancer $(24,25)$. Long noncoding RNAs (lncRNAs) have been identified by their specific association with prostate tissue and altered expression during tumorigenesis, progression and metastasis (26-28). LncRNAs function as oncogenes, such as $C D K N 2 B-A S 1$, which functions to silence the cyclin-dependent kinase inhibitor CDKN2B, or as tumor suppressors, such as growth arrest-specific 5 (GAS5). Overexpression of certain oncogenic lncRNAs may promote cancer hallmarks via the modulation of AR and other important signaling pathways (29).

\section{Genetic biomarkers for screening and detection of early cancer}

Extensive cancer research investigating the underlying molecular mechanisms, screening and validation of genetic aberration-based biomarkers from numerous patient cohorts, has been performed (Table I). The results suggest that tumor-associated genomic aberrations may be utilized for cancer screening, diagnosis, risk prognosis, therapy prediction and outcome assessment (30-32). Blood PSA tests are frequently used to screen and detect early-stage cancer (33). A biopsy is typically recommended to confirm the cancer is clinically relevant (defined as a PSA value of $>3-4 \mathrm{ng} / \mathrm{ml}$ ). However, this blood test is not able to distinguish indolent cancer from aggressive cancer, which may lead to over-diagnosis and over-treatment of low-risk cancer cases $(2,30)$. LncRNA prostate cancer antigen 3 (PCA3), which is overexpressed in $\sim 5 \%$ of prostate tumors, may be a complementary test that improves the probability of a cancer-positive biopsy (28-31). A previous meta-analysis of 46 cohort studies demonstrated that the sensitivity and specificity achieved by the urine PCA3 test was 0.65 and 0.73 , respectively (34). A PCA3 score threshold level of 35 is typically applied as the best test of accuracy. Overexpression of $P C A 3$ has been reported to modulate AR pro-survival signaling, and to promote cancer cell growth and survival during the early stages of tumorigenesis (29).

\section{Genetic biomarkers for risk stratification of aggressive cancer}

Overexpression of prostate cancer associated transcript 1 (PCAT1), another IncRNA, has been identified in a subset of high-grade localized (GS, $\geq 7)$ and metastatic tumors (Table I) $(27,28)$. PCAT1 functions to promote cancer cell proliferation through mediating the upregulation of $c-M y c$ and the repression of breast cancer 2, early onset (BRCA2) $(35,36)$. Overexpression of alpha-methylacyl-CoA racemase (AMACR) is associated with an increased risk of cancer in numerous ethnicities, which has been evaluated using meta-analyses of 22 cohort and case-series studies (37). A previous cohort study demonstrated that overexpression at 8.8-, >12- and $>18$-fold of AMACR observed from tumors, associated with the increased risk from minimally invasive to aggressive tumors, concordantly (38). Due to the reduced level of upregulation in metastatic cancer, an optimized expression threshold level of AMACR may be able to predict an increased risk of an aggressive cancer and its progression, PSA recurrence and cancer-specific mortality (39). ETS gene fusions, including ERG-TMPRSS2, are involved in cancer cell invasion and metastatic characteristics $(15,40)$. ETS fusion-positive cancer is associated with disease aggressiveness and poor prognosis $(15,41)$, which may aid in effective clinical choices for re-biopsy (31). For an ETS fusion-negative cancer subtype, PTEN loss may be an independent indicator of poor survival and the increased risk of lethal progression following prostatectomy $(42,43)$. Epigenetic alteration of tumor suppressors, DNA damage repair or other repair genes through hypermethylation 
Table I. List of representative genetic biomarkers used for cancer screening, detection and risk prognosis.

\begin{tabular}{|c|c|c|c|}
\hline Author, year & Cancer biomarker & Function & (Refs.) \\
\hline $\begin{array}{l}\text { Mouraviev et al, 2016; } \\
\text { Cui et al, } 2016\end{array}$ & Urine $P C A 3$ & Improve detection of early cancer & $(28,34)$ \\
\hline $\begin{array}{l}\text { Prensner et al, 2011; } \\
\text { Mouraviev et al, } 2016\end{array}$ & PCAT1 & $\begin{array}{l}\text { Prognosis of high-grade } \\
\text { and metastatic cancer risk }\end{array}$ & $(27,28)$ \\
\hline $\begin{array}{l}\text { Jiang et al, 2013; } \\
\text { Yu et al, } 2013\end{array}$ & $A M A C R$ & Prognosis of cancer risk & $(37,38)$ \\
\hline $\begin{array}{l}\text { Schrecengost et al, 2013; } \\
\text { Hägglöf et al, } 2014\end{array}$ & ERG-TMPRSS2 & Prognosis of cancer aggressiveness & $(15,41)$ \\
\hline $\begin{array}{l}\text { Reid et al, 2010; } \\
\text { Ahearn et al, } 2016\end{array}$ & PTEN loss & $\begin{array}{l}\text { Prognosis of poor survival } \\
\text { and the risk of lethal progression } \\
\text { following prostatectomy }\end{array}$ & $(42,43)$ \\
\hline $\begin{array}{l}\text { Bastian et al, 2004; } \\
\text { Florl et al, } 2004\end{array}$ & GSTP1 hypermethylation & Detection of cancer & $(25,45)$ \\
\hline Hieronymus et al, 2014 & CNA of tumor genome & $\begin{array}{l}\text { Prognosis of recurrence and } \\
\text { metastasis of primary cancer }\end{array}$ & (23) \\
\hline Martin et al, 2016 & $\begin{array}{l}12 \text { gene-based prostate } \\
\text { cancer score }\end{array}$ & Prognosis of early-stage cancer risk & $(47)$ \\
\hline Cuzick et al, 2011 & $\begin{array}{l}31 \text { gene-based cell } \\
\text { cycle progression score }\end{array}$ & $\begin{array}{l}\text { Risk prognosis of cancer-specific } \\
\text { mortality }\end{array}$ & $(48)$ \\
\hline Alshalalfa et al, 2015 & $\begin{array}{l}22 \text { gene-based prostate } \\
\text { cancer classifier }\end{array}$ & $\begin{array}{l}\text { Risk prognosis of metastasis } \\
\text { following surgery }\end{array}$ & $(49)$ \\
\hline Peng et al, 2014 & $\begin{array}{l}3 \text { gene-based expression } \\
\text { signature }\end{array}$ & Risk prognosis of overall survival time & $(50)$ \\
\hline
\end{tabular}

PCA3, prostate cancer antigen 3; PCAT1, prostate cancer associated transcript 1; AMACR, alpha-methylacyl-CoA racemase; ERG-TMPRSS2, transcriptional regulator erg-transmembrane protease serine 2; PTEN, phosphatase and tensin homolog; GSTP1, glutathione S-transferase Pi 1; CAN, copy number alteration.

is associated with prostate cancer tumorigenesis, and these alterations are frequently identified in solid tumor cells and the bodily fluids of patients $(25,44)$. Glutathione S-transferase Pi 1 (GSTP1) hypermethylation was detected in $70 \%$ of the surveyed patients with cancer and was distinctive compared with non-neoplastic tissues $(25,45)$. Genome sequencing from two patient cohorts demonstrated that copy number alteration in a fractured tumor genome may be an independent prognostic biomarker for recurrence and metastasis of primary cancer following prostatectomy (23).

\section{Expression score of a panel of genetic biomarkers for risk stratification}

The profiling of a panel of genetic aberrations may provide an informative and accurate stratification of cancer risk (Table I) (46). This may be able to improve clinical decision-making at the stage of biopsy, when combined with standard pathological and clinical factors (47). The Oncotype DX ${ }^{\circledR}$ Prostate Cancer assay scores the aberrant expression signatures of 12 cancer-associated genes, which are part of the AR signaling, stromal response, cellular organization and proliferation pathways (47). The score ranges from 0-100 and provides a proportional assessment of risk for early-stage cancer for diagnostic use. The Cell Cycle
Progression score evaluates the aberrant mRNA expression of 31 cell cycle-associated genes (48). The score ranges from -2 to 6 , and are used to predict the cancer-specific mortality of high to low risk cancer after 10 years for clinically localized cancer. Decipher ${ }^{\circledR}$ Prostate Cancer Classifier profiles the expression signature of 22 aggressive cancer-associated RNA markers, which are involved in the biological processes of proliferation, differentiation, adhesion/motility, cell cycle progression and the immune response (49). The categories of low-, intermediate- and high-risk levels are used to predict the probability of metastasis within five years following surgery. A simple expression signature of three genes (vestigial-like family member 3, insulin-like growth factor binding protein 3 and coagulation factor III) was used to categorize the high-, intermediate- and low-risk levels of cancer and predicted a median overall survival time of $3.23,4.00$ and 9.85 years, respectively (50).

\section{Non-invasive genetic biomarker test}

As an alternative to the tumor tissue-based invasive testing, liquid biopsy, using cell-free DNA/RNA and circulating tumor cells (CTCs), is a non-invasive approach of detecting cancer genetic characteristics in bodily fluid. Cancer cells secrete genomic fragments into the circulatory system and 
this provides a novel approach for a cancer diagnostic test (51). CTCs may be potential biomarkers to predict effective therapies in patients with castration-resistant cancer $(52,53)$. Increased levels of blood CTCs are associated with poor survival outcome for patients with prostate cancer (52). Aside from the typically used blood-based PSA test, the urine-based expression test of IncRNA PCA3 may provide information for the early detection of cancer $(28,34)$. Signature analysis of a panel of genes (PCA3, serine peptidase inhibitor Kazal type 1, Golgi phosphoprotein 2 and TMPRSS2:ERG) identified that their presence in urine was demonstrated to be more effective, compared with testing for $P C A 3$ alone, for the early detection of cancer (46). A test accuracy level (the area under the receiver-operating characteristic curve) of 0.758 was achieved using the multi-gene model, compared with 0.662 by $P C A 3$ detection alone (46). A previous study reported that GSTPI hypermethylation was detected in plasma in $56 \%$ of cancer cases diagnosed as tumor stage T2-3, and in 93\% of those with the tumor stage $\mathrm{T} 4 \mathrm{~N}+$ or metastasis (25). This suggests that the methylation level of GSTP1 is associated with advanced-stage cancer.

The cancer risk score, which is based on the expression signatures of Homeobox C6 (HOXC6) and Distal-less homeobox 1 (DLX1) mRNAs in urine, may improve the identification of high-grade tumors, when combined with standard clinical risk factors (54). The HOXC6 and DLXI homeobox genes are upregulated in prostate cancer cells and their expression increases during the progression of cancer to a higher-grade, castration-resistant and metastatic stage $(55,56)$. The Mi-Prostate Score combined the expression signatures of urine ERG-TMPRSS2 and PCA3 with serum PSA, may improve the prediction of cancer risk and high-grade cancer following biopsy (57). A novel urine exosome 3-gene expression assay, which includes sterile alpha motif pointed domain, $E R G$ and $P C A 3$, may distinguish high-grade tumors (GS, $\geq 7$ ) from low-risk $(\mathrm{GS}, \leq 6)$ and benign disease when combined with standard factors (58). These non-invasive biomarker tests have demonstrated the capability to provide effective identification of clinically relevant cancer, therefore aiding biopsy decision-making.

\section{Therapies targeting to tumor genetic aberrations}

Heterogeneous alterations of genetic characteristics contribute to prostate cancer onset, progression and metastasis. Individual patients have a distinct pattern of genetic alterations; therefore, treatment should be guided by the profile of diagnostic biomarkers $(14,22,32)$. The AR signaling axis is a major target for numerous hormone therapies, throughout the stages of cancer (59-61). Once castration resistance develops, cancer cells harboring aberrant $A R$ markedly evolve. Potent drugs, including AR antagonists and CYP17 inhibitors, may be used to inhibit the adapted AR and microenvironment due to androgen depletion (59,60). For ETS fusion-positive cancer, agents inhibiting fusion cofactors, such as DNA damage repair genes [poly(ADP-ribose) polymerase (PARP) 1, DNA-protein kinase $(P K)$ and histone deacetylase 1], demonstrated a preferential effect in this subtype during clinical phase studies (61). The PTEN gene is a suppressor of the phosphoinositide-3-kinase/protein kinase $\mathrm{B} / \mathrm{mechanistic}$ target of rapamycin (PI3K/Akt/mTOR) signaling pathway. Its loss leads to uncontrolled signaling that promotes cancer cell proliferation and growth. Therefore, drugs that inhibit the altered PI3K/Akt/mTOR signaling activity may be used to treat a cancer with PTEN loss or mutation $(42,43,61)$. Cancer cells with defective mutations in DNA repair genes (including $B R C A 2$ and $A T M$ ) have increased susceptibility to the impairment of the base excision repair pathway; therefore, patients with this genetic defect may benefit from treatment with platinum agents or PARP inhibitors (61).

The genetic alterations in a tumor may also be used as a predictor for the effectiveness of therapy. High expression levels of nuclear $A R$ with the combined presence of cytoplasmic $C Y P 17$ demonstrated an improved response to AR targeted therapy, including abiraterone and enzalutamide, for cancer cases with bone metastasis (59,61-63). AR-V7 splice variant is able to constitutively activate AR target genes without the requirement of androgen binding. Its expression has been hypothesized as a primary underlying mechanism of resistance to abiraterone and enzalutamide $(59,61)$. Cancer with high expression levels of the drug efflux transporter genes, including multidrug resistance protein 1 (MDR1) and certain $\beta$-tubulin isotypes ( $\beta I I I$-tubulin), demonstrate increased resistance to chemotherapies, such as docetaxel (64). Reduction of the intracellular docetaxel through the high substrate affinity of MDR1 or altered microtubule binding structure by the isotype $\beta$ III-tubulin, contributes to taxane resistance $(62,64,65)$. A previous archival cohort study reported that patients with downregulated $E$-Cadherin were associated with poor relapse outcomes following radiation therapy (66).

\section{Discussion}

Cancer-associated genetic alterations and heterogeneity may be utilized to improve cancer diagnosis, subtype identification and risk stratification, but also may be targeted for therapeutic intervention. Oncogenetic testing and biomarker profiling demonstrates the increasing importance to facilitate the optimal choice of drugs based on the alterations observed in individual patients, particularly for targeted therapy $(67,68)$. Therefore, patients would receive the appropriate treatment at an early stage to reduce the risk of mortality and medical costs. Novel cancer drugs are developed by using a drug-diagnostic co-development model (67). Drugs developed using this model target the matched subsets of patients defined by clinical biomarkers. Clinical trials have demonstrated a high success rate for drugs that are developed using biomarkers in patients with non-small cell lung cancer (68).

The analysis of residual cancer genomic characteristics allows the monitoring of drug response and the assessment of therapy outcomes and relapse for individual patients. Drug resistance is a significant challenge associated with cancer therapy $(62,63,65,69)$. A cancer cell with alterations in drug targeting sites, activation of alternative survival pathways and altered expression of drug influx/efflux transporters may result in the development of a resistant generation of cancer cells. The evaluation of novel mutations may be used to predict drug resistance. Non-invasive tests provide an accessible solution 
for the continuous monitoring of a cancer during the course of treatment.

Microarrays, which aided the development of cancer genomics, have been identified as an effective tool for the detection of cytogenetic aberrations, including copy number, altered gene expression and single nucleotide polymorphism $(70,71)$. Effective novel biotechnologies, such as next-generation sequencing, have aided significant advances in the comprehensive analysis of cancer genomic alterations that has a single-base resolution, is genome-wide and is high-throughput $(21,22,27)$. Targeted and deep DNA sequencing provides an in-depth evaluation of clinically relevant and low-frequency genetic variations $(72,73)$. Targeted RNA sequencing allows the analysis of complex transcriptomes and gene fusions $(74,75)$. Long-read and linked-read sequencing is able to identify complex genetic aberrations, such as the haplotype of genetic aberrations and genomic rearrangements (76,77). Single-cell sequencing has the ability to evaluate numerous cancer sub-clones, including those that confer drug-resistance (78). The primary obstacle for non-invasive testing is the inconsistent recovery and low-abundance of tumor circulating DNA and RNA. Advanced technologies may possess the ability to sensitively detect the genomic alterations of tumor cells in circulation (79), and continue to improve the investigation of challenges in field of personalized cancer therapy.

\section{References}

1. Lowrance WT and Scardino PT: Predictive models for newly diagnosed prostate cancer patients. Rev Urol 11: 117-126, 2009.

2. Loeb S, Bjurlin MA, Nicholson J, Tammela TL, Penson DF, Carter HB, Carroll P and Etzioni R: Overdiagnosis and overtreatment of prostate cancer. Eur Urol 65: 1046-1055, 2014.

3. Zhou Y, Bolton EC and Jones JO: Androgens and androgen receptor signaling in prostate tumorigenesis. J Mol Endocrinol 54: R15-R29, 2015.

4. Brooke GN, Parker MG and Bevan CL: Mechanisms of androgen receptor activation in advanced prostate cancer: Differential co-activator recruitment and gene expression. Oncogene 27: 2941-2950, 2008.

5. Perner S, Cronauer MV, Schrader AJ, Klocker H, Culig Z and Baniahmad A: Adaptive responses of androgen receptor signaling in castration-resistant prostate cancer. Oncotarget 6 : 35542-35555, 2015.

6. Grant CM and Kyprianou N: Epithelial mesenchymal transition (EMT) in prostate growth and tumor progression. Transl Androl Urol 2: 202-211, 2013

7. Khan MI, Hamid A, Adhami VM, Lall RK and Mukhtar H: Role of epithelial mesenchymal transition in prostate tumorigenesis. Curr Pharm Des 21: 1240-1248, 2015.

8. Gravdal K, Halvorsen OJ, Haukaas SA and Akslen LA: A switch from $\mathrm{E}$-cadherin to $\mathrm{N}$-cadherin expression indicates epithelial to mesenchymal transition and is of strong and independent importance for the progress of prostate cancer. Clin Cancer Res 13: 7003-7011, 2007.

9. Lu-Yao GL, Albertsen PC, Moore DF, Lin Y, DiPaola RS and Yao SL: Fifteen-year outcomes following conservative management among men aged 65 years or older with localized prostate cancer. Eur Urol 68: 805-811, 2015.

10. Lu-Yao GL, Albertsen PC, Moore DF, Shih W, Lin Y, DiPaola RS Barry MJ, Zietman A, O'Leary M, Walker-Corkery E and Yao SL: Outcomes of localized prostate cancer following conservative management. JAMA 302: 1202-1209, 2009.

11. Rodrigues G, Warde P, Pickles T, Crook J, Brundage M, Souhami L and Lukka H; Genitourinary Radiation Oncologists of Canada: Pre-treatment risk stratification of prostate cancer patients: A critical review. Can Urol Assoc J 6: 121-127, 2012.

12. Ma Q and Lu AY: Pharmacogenetics, pharmacogenomics, and individualized medicine. Pharmacol Rev 63: 437-459, 2011.
13. Wallace TJ, Torre T, Grob M, Yu J, Avital I, Brücher B, Stojadinovic A and Man YG: Current approaches, challenges and future directions for monitoring treatment response in prostate cancer. J Cancer 5: 3-24, 2014.

14. Aftimos PG, Barthelemy P and Awada A: Molecular biology in medical oncology: Diagnosis, prognosis, and precision medicine. Discov Med 17: 81-91, 2014.

15. Schrecengost R and Knudsen KE: Molecular pathogenesis and progression of prostate cancer. Semin Oncol 40: 244-258, 2013.

16. Wang Q, Li W, Liu XS, Carroll JS, Jänne OA, Keeton EK, Chinnaiyan AM,Pienta KJ and Brown M: A hierarchical network of transcription factors governs androgen receptor-dependent prostate cancer growth. Mol Cell 27: 380-392, 2007.

17. Shaikhibrahim $Z$ and Wernert N: ETS transcription factors and prostate cancer: The role of the family prototype ETS-1 (Review). Int J Oncol 40: 1748-1754, 2012.

18. Cancer Genome Atlas Research Network: The molecular taxonomy of primary prostate cancer. Cell 163: 1011-1025, 2015.

19. Integrative Onco Genomics: Prostate adenocarcinoma. https:// www.intogen.org/search?cancer $=$ PRAD\#drivers. Accessed September 5, 2016.

20. Boysen G, Barbieri CE, Prandi D, Blattner M, Chae SS, Dahija A, Nataraj S, Huang D, Marotz C, Xu L, et al: SPOP mutation leads to genomic instability in prostate cancer. Elife 4: pii: e09207, 2015.

21. Grasso CS, Wu YM, Robinson DR, Cao X, Dhanasekaran SM, Khan AP, Quist MJ, Jing X, Lonigro RJ, Brenner JC, et al: The mutational landscape of lethal castration-resistant prostate cancer. Nature 487: 239-243, 2012.

22. Beltran H, Yelensky R, Frampton GM, Park K, Downing SR, MacDonald TY, Jarosz M, Lipson D, Tagawa ST, Nanus DM, et al: Targeted next-generation sequencing of advanced prostate cancer identifies potential therapeutic targets and disease heterogeneity. Eur Urol 63: 920-926, 2013.

23. Hieronymus H, Schultz N, Gopalan A, Carver BS, Chang MT, Xiao Y, Heguy A, Huberman K, Bernstein M, Assel M, et al: Copy number alteration burden predicts prostate cancer relapse. Proc Natl Acad Sci USA 111: 11139-11144, 2014.

24. Mahapatra S, Klee EW, Young CY, Sun Z, Jimenez RE, Klee GG, Tindall DJ and Donkena KV: Global methylation profiling for risk prediction of prostate cancer. Clin Cancer Res 18: 2882-2895, 2012.

25. Bastian PJ, Yegnasubramanian S, Palapattu GS, Rogers CG, Lin X, De Marzo AM and Nelson WG: Molecular biomarker in prostate cancer: The role of $\mathrm{CpG}$ island hypermethylation. Eur Urol 46: 698-708, 2004

26. Rönnau CG, Verhaegh GW, Luna-Velez MV and Schalken JA: Noncoding RNAs as novel biomarkers in prostate cancer. Biomed Res Int 2014: 591703, 2014.

27. Prensner JR, Iyer MK, Balbin OA, Dhanasekaran SM, Cao Q, Brenner JC, Laxman B, Asangani IA, Grasso CS, Kominsky HD, et al: Transcriptome sequencing across a prostate cancer cohort identifies PCAT-1, an unannotated lincRNA implicated in disease progression. Nat Biotechnol 29: 742-749, 2011.

28. Mouraviev V, Lee B, Patel V, Albala D, Johansen TE, Partin A, Ross A and Perera RJ: Clinical prospects of long noncoding RNAs as novel biomarkers and therapeutic targets in prostate cancer. Prostate Cancer Prostatic Dis 19: 14-20, 2016.

29. Ferreira LB, Palumbo A, de Mello KD, Sternberg C, Caetano MS de Oliveira FL, Neves AF, Nasciutti LE, Goulart LR and Gimba ER: PCA3 noncoding RNA is involved in the control of prostate-cancer cell survival and modulates androgen receptor signaling. BMC Cancer 12: 507, 2012.

30. Prensner JR, Rubin MA, Wei JT and Chinnaiyan AM: Beyond PSA: The next generation of prostate cancer biomarkers. Sci Transl Med 4: 127rv3, 2012.

31. Crawford ED, Ventii K and Shore ND: New biomarkers in prostate cancer. Oncology (Williston Park) 28: 135-142, 2014.

32. Schoenborn JR, Nelson P and Fang M: Genomic profiling defines subtypes of prostate cancer with the potential for therapeutic stratification. Clin Cancer Res 19: 4058-4066, 2013.

33. Catalona WJ, Smith DS, Ratliff TL, Dodds KM, Coplen DE, Yuan JJ, Petros JA and Andriole GL: Measurement of prostate-specific antigen in serum as a screening test for prostate cancer. N Engl J Med 324: 1156-1161, 1991.

34. Cui Y, Cao W, Li Q, Shen H, Liu C, Deng J, Xu J and Shao Q: Evaluation of prostate cancer antigen 3 for detecting prostate cancer: A systematic review and meta-analysis. Sci Rep 6: 25776, 2016. 
35. Prensner JR, Chen W, Han S, Iyer MK, Cao Q, Kothari V, Evans JR, Knudsen KE, Paulsen MT, Ljungman M, et al: The long non-coding RNA PCAT-1 promotes prostate cancer cell proliferation through cMyc. Neoplasia 16: 900-908, 2014.

36. Prensner JR, Chen W, Iyer MK, Cao Q, Ma T, Han S, Sahu A, Malik R, Wilder-Romans K, Navone N, et al: PCAT-1, a long noncoding RNA, regulates BRCA2 and controls homologous recombination in cancer. Cancer Res 74: 1651-1660, 2014.

37. Jiang N, Zhu S, Chen J, Niu Y and Zhou L: A-methylacyl-CoA racemase (AMACR) and prostate-cancer risk: A meta-analysis of 4,385 participants. PLoS One 8: e74386, 2013.

38. Yu YP, Landsittel D, Jing L, Nelson J, Ren B, Liu L, McDonald C, Thomas R, Dhir R, Finkelstein S, et al: Gene expression alterations in prostate cancer predicting tumor aggression and preceding development of malignancy. J Clin Oncol 22: 2790-2799, 2004.

39. Rubin MA, Bismar TA, Andrén O, Mucci L, Kim R, Shen R, Ghosh D, Wei JT, Chinnaiyan AM, Adami HO, et al: Decreased alpha-methylacyl CoA racemase expression in localized prostate cancer is associated with an increased rate of biochemical recurrence and cancer-specific death. Cancer Epidemiol Biomarkers Prev 14: 1424-1432, 2005.

40. Feng FY, Brenner JC, Hussain M and Chinnaiyan AM: Molecular pathways: Targeting ETS gene fusions in cancer. Clin Cancer Res 20: 4442-4448, 2014

41. Hägglöf C, Hammarsten P, Strömvall K, Egevad L, Josefsson A, Stattin P, Granfors T and Bergh A: TMPRSS2-ERG expression predicts prostate cancer survival and associates with stromal biomarkers. PLoS One 9: e86824, 2014.

42. Reid AH, Attard G, Ambroisine L, Fisher G, Kovacs G, Brewer D, Clark J, Flohr P, Edwards S, Berney DM, et al: Molecular characterisation of ERG, ETV1 and PTEN gene loci identifies patients at low and high risk of death from prostate cancer. $\mathrm{Br} J$ Cancer 102: 678-684, 2010.

43. Ahearn TU, Pettersson A, Ebot EM, Gerke T, Graff RE, Morais CL, Hicks JL, Wilson KM, Rider JR, Sesso HD, et al: A prospective investigation of PTEN loss and ERG expression in lethal prostate cancer. J Natl Cancer Inst 108: pii: djv346, 2015.

44. Shivapurkar N and Gazdar AF: DNA methylation based biomarkers in non-invasive cancer screening. Curr Mol Med 10: 123-132, 2010.

45. Florl AR, Steinhoff C, Müller M, Seifert HH, Hader C, Engers R, Ackermann R and Schulz WA: Coordinate hypermethylation at specific genes in prostate carcinoma precedes LINE-1 hypomethylation. Br J Cancer 91: 985-994, 2004.

46. Laxman B, Morris DS, Yu J, Siddiqui J, Cao J, Mehra R Lonigro RJ, Tsodikov A, Wei JT, Tomlins SA and Chinnaiyan AM: A first-generation multiplex biomarker analysis of urine for the early detection of prostate cancer. Cancer Res 68: 645-649, 2008.

47. Martin NE: New developments in prostate cancer biomarkers Curr Opin Oncol 28: 248-252, 2016.

48. Cuzick J, Swanson GP, Fisher G, Brothman AR, Berney DM, Reid JE, Mesher D, Speights VO, Stankiewicz E, Foster CS, et al: Prognostic value of an RNA expression signature derived from cell cycle proliferation genes in patients with prostate cancer: A retrospective study. Lancet Oncol 12: 245-255, 2011

49. Alshalalfa M, Crisan A, Vergara IA, Ghadessi M, Buerki C, Erho N, Yousefi K, Sierocinski T, Haddad Z, Black PC, et al: Clinical and genomic analysis of metastatic prostate cancer progression with a background of postoperative biochemical recurrence. BJU Int 116: 556-567, 2015.

50. Peng Z, Skoog L, Hellborg H, Jonstam G, Wingmo IL, Hjälm-Eriksson M, Harmenberg U, Cedermark GC, Andersson K, Ahrlund-Richter L, et al: An expression signature at diagnosis to estimate prostate cancer patients' overall survival. Prostate Cancer Prostatic Dis 17: 81-90, 2014.

51. Chun FK, Müller I, Lange I, Friedrich MG, Erbersdobler A, Karakiewicz PI, Graefen M, Pantel K, Huland H and Schwarzenbach H: Circulating tumour-associated plasma DNA represents an independent and informative predictor of prostate cancer. BJU Int 98: 544-548, 2006.

52. Danila DC, Fleisher M and Scher HI: Circulating tumor cells as biomarkers in prostate cancer. Clin Cancer Res 17: 3903-3912, 2011.

53. Rapisuwon S, Vietsch EE and Wellstein A: Circulating biomarkers to monitor cancer progression and treatment. Comput Struct Biotechnol J 14: 211-222, 2016.
54. Van Neste L, Hendriks RJ, Dijkstra S, Trooskens G, Cornel EB Jannink SA, de Jong H, Hessels D, Smit FP, Melchers WJ, et al: Detection of high-grade prostate cancer using a urinary molecular biomarker-based risk score. Eur Urol 70: 740-748, 2016.

55. Leyten GH, Hessels D, Smit FP, Jannink SA, de Jong H, Melchers WJ, Cornel EB, de Reijke TM, Vergunst H, Kil P, et al: Identification of a candidate gene panel for the early diagnosis of prostate cancer. Clin Cancer Res 21: 3061-3070, 2015.

56. Alinezhad S, Väänänen RM, Mattsson J, Li Y, Tallgrén T, Tong Ochoa N, Bjartell A, Åkerfelt M, Taimen P, Boström PJ, et al: Validation of novel biomarkers for prostate cancer progression by the combination of bioinformatics, clinical and functional studies. PLoS One 11: e0155901, 2016.

57. Tomlins SA, Day JR, Lonigro RJ, Hovelson DH, Siddiqui J, Kunju LP, Dunn RL, Meyer S, Hodge P, Groskopf J, et al: Urine TMPRSS2:ERG plus PCA3 for individualized prostate cancer risk assessment. Eur Urol 70: 45-53, 2016.

58. McKiernan J, Donovan MJ, O'Neill V, Bentink S, Noerholm M, Belzer S, Skog J, Kattan MW, Partin A, Andriole G, et al: A novel urine exosome gene expression assay to predict high-grade prostate cancer at initial biopsy. JAMA Oncol 2: 882-889, 2016.

59. Crawford ED, Higano CS, Shore ND, Hussain M and Petrylak DP: Treating patients with metastatic castration resistant prostate cancer: A comprehensive review of available therapies. J Urol 194: 1537-1547, 2015.

60. Mitsiades N: A road map to comprehensive androgen receptor axis targeting for castration-resistant prostate cancer. Cancer Res 73: 4599-4605, 2013.

61. Khemlina G, Ikeda S and Kurzrock R: Molecular landscape of prostate cancer: Implications for current clinical trials. Cancer Treat Rev 41: 761-766, 2015.

62. Chi K, Hotte SJ, Joshua AM, North S, Wyatt AW, Collins LL and Saad F: Treatment of mCRPC in the AR-axis-targeted therapy-resistant state. Ann Oncol 26: 2044-2056, 2015.

63. Kahn B, Collazo J and Kyprianou N: Androgen receptor as a driver of therapeutic resistance in advanced prostate cancer. Int J Biol Sci 10: 588-595, 2014.

64. Antonarakis ES and Armstrong AJ: Evolving standards in the treatment of docetaxel-refractory castration-resistant prostate cancer. Prostate Cancer Prostatic Dis 14: 192-205, 2011.

65. Housman G, Byler S, Heerboth S, Lapinska K, Longacre M, Snyder N and Sarkar S: Drug resistance in cancer: An overview. Cancers (Basel) 6: 1769-1792, 2014.

66. Kachroo N, Warren AY and Gnanapragasam VJ: Multi-transcript profiling in archival diagnostic prostate cancer needle biopsies to evaluate biomarkers in non-surgically treated men. BMC Cancer 14: 673, 2014.

67. Jørgensen JT: Drug-diagnostics co-development in oncology. Front Oncol 4: 208,2014.

68. Olsen D and Jørgensen JT: Companion diagnostics for targeted cancer drugs-clinical and regulatory aspects. Front Oncol 4: 105, 2014.

69. Rueff J and Rodrigues AS: Cancer drug resistance: A brief overview from a genetic viewpoint. Methods Mol Biol 1395: 1-18, 2016.

70. Li MM, Monzon FA, Biegel JA, Jobanputra V, Laffin JJ, Levy B, Leon A, Miron P, Rossi MR, Toruner G, et al: A multicenter, cross-platform clinical validation study of cancer cytogenomic arrays. Cancer Genet 208: 525-536, 2015.

71. Trevino V, Falciani $F$ and Barrera-Saldaña HA: DNA microarrays: A powerful genomic tool for biomedical and clinical research. Mol Med 13: 527-541, 2007.

72. Myllykangas S and Ji HP: Targeted deep resequencing of the human cancer genome using next-generation technologies. Biotechnol Genet Eng Rev 27: 135-158, 2010.

73. Kinde I, Wu J, Papadopoulos N, Kinzler KW and Vogelstein B: Detection and quantification of rare mutations with massively parallel sequencing. Proc Natl Acad Sci USA 108: 9530-9535, 2011.

74. Mercer TR, Gerhardt DJ, Dinger ME, Crawford J, Trapnell C, Jeddeloh JA, Mattick JS and Rinn JL: Targeted RNA sequencing reveals the deep complexity of the human transcriptome. Nat Biotechnol 30: 99-104, 2012

75. Scolnick JA, Dimon M, Wang IC, Huelga SC and Amorese DA: An efficient method for identifying gene fusions by targeted RNA sequencing from fresh frozen and FFPE samples. PLoS One 10: e0128916, 2015 . 
76. Weirather JL, Afshar PT, Clark TA, Tseng E, Powers LS, Underwood JG, Zabner J, Korlach J, Wong WH and Au KF: Characterization of fusion genes and the significantly expressed fusion isoforms in breast cancer by hybrid sequencing. Nucleic Acids Res 43: e116, 2015.

77. Zheng GX, Lau BT, Schnall-Levin M, Jarosz M, Bell JM, Hindson CM, Kyriazopoulou-Panagiotopoulou S, MasquelierDA, Merrill L, Terry JM, et al: Haplotyping germline and cancer genomes with high-throughput linked-read sequencing. Nat Biotechnol 34: 303-311, 2016.
78. Gawad C, Koh W and Quake SR: Single-cell genome sequencing: Current state of the science. Nat Rev Genet 17: 175-188, 2016.

79. Newman AM, Bratman SV, To J, Wynne JF, Eclov NC, Modlin LA, Liu CL, Neal JW, Wakelee HA, Merritt RE, et al: An ultrasensitive method for quantitating circulating tumor DNA with broad patient coverage. Nat Med 20: 548-554, 2014. 